\title{
Article \\ On-Surface Synthesis of Ligands to Elaborate Coordination Polymers on an Au(111) Surface
}

\author{
Elie Geagea, Judicael Jeannoutot, Louise Morgenthaler, Simon Lamare, Frank Palmino and Frédéric Chérioux *
}

Citation: Geagea, E.; Jeannoutot, J.; Morgenthaler, L.; Lamare, S.; Palmino, F; Chérioux, F. On-Surface Synthesis of Ligands to Elaborate Coordination Polymers on an $\mathrm{Au}(111)$ Surface. Nanomaterials 2021, 11, 2102. https:// doi.org/10.3390/nano11082102

Academic Editor:

Carlos Sánchez-Sánchez

Received: 9 July 2021

Accepted: 11 August 2021

Published: 19 August 2021

Publisher's Note: MDPI stays neutral with regard to jurisdictional claims in published maps and institutional affiliations.

Copyright: (c) 2021 by the authors. Licensee MDPI, Basel, Switzerland. This article is an open access article distributed under the terms and conditions of the Creative Commons Attribution (CC BY) license (https:/ / creativecommons.org/licenses/by/ $4.0 /)$.
FEMTO-ST, CNRS, Université de Franche-Comté, 15B Avenue des Montboucons, CEDEX, 25030 Besancon, France; elie.geagea@femto-st.fr (E.G.); judicael.jeannoutot@femto-st.fr (J.J.); louise.morgenthaler@yahoo.fr (L.M.); simon.lamare.pro@hotmail.fr (S.L.); frank.palmino@univ-fcomte.fr (F.P.)

* Correspondence: frederic.cherioux@femto-st.fr

\begin{abstract}
On-surface metal-organic polymers have emerged as a class of promising 2D materials. Here, we propose a new strategy to obtain coordination polymers by transforming supramolecular networks into coordination polymers by surface-assisted cyclo-dehydrogenation of organic building blocks. All nanostructures are fully characterized by using scanning tunneling microscopy under ultra-high vacuum on a gold surface. We demonstrated that the balance between molecule-molecule interaction and molecule-substrate interaction can be drastically modified by a strong modification of the geometry of the molecules thanks to a thermal annealing. This new way is an efficient method to elaborate on-surface coordination polymers.
\end{abstract}

Keywords: scanning tunnelling microscopy; on-surface synthesis; coordination polymers

\section{Introduction}

During the past two decades, self-organization of molecular materials on surfaces has been widely investigated in the case of organic molecules and molecular objects deposited on different kind of substrates [1-5]. More recently, on-surface synthesis has emerged to provide the fabrication of covalent nanostructures [6-20]. All these nanostructures have been obtained by bottom-up approaches and their structure are atomically-precise, as proven by scanning probe microscopies, that can be used for great potential applications in molecular electronics, spintronics, energy, catalysis and other fields. Among all types of nanostructures, coordination polymers have attracted attention because coordination bonds are reversible, leading to the possibility to self-reparation by bond scission and reformation in order to achieve the formation of defect-free nanostructures [21-25]. These polymers can be directly obtained on crystalline substrate by the deposition of polyfunctional organic linkers that are able to coordinate adatoms of the surface or co-deposited metallic atoms in ultra-high vacuum. These organic linkers are able to coordinate metallic atoms or cations without any further action, because their coordination sites are in-the-plane and close to the underlying surface. The formation of the surface-confined coordination polymers is mainly governed by the balance between molecule-molecule and molecule-surface interactions, bond strength, reversibility of bond formation, precursor diffusion and their surfaceconcentration [2]. Finally, the nature of the metal atoms plays a key-role in the formation of the coordination polymers [21]. By tuning all these parameters, many surface-confined coordination polymers have been successfully achieved [20-23]. However, in most of cases, the underlying surface does not modify the ability of the organic linkers to coordinate metal centers. As on-surface chemistry gives the opportunity to create new building blocks only accessible when they are adsorbed at the surface, we propose to transform an organic molecule into an organic linker by surface-assisted reaction.

Here, we report a surface-assisted reaction that transforms organic molecules involved in large extended 2D-supramolecular networks into organic linkers being able to coordinate adatoms of the surface to give 1D coordination polymers. Experiments were performed 
on an $\mathrm{Au}(111)$ surface in ultra-high vacuum (UHV). All adsorbates are fully characterized by scanning tunneling microscopy that provides images with submolecular resolution. By using a surface-assisted cyclodehydrogenation reaction, we switch a purely $2 \mathrm{D}$ supramolecular network to coordination polymer by a controlled flattening of this organic molecule that gives it the ability to coordinate metal adatoms.

\section{Materials and Methods}

\subsection{Synthesis}

All reagents were purchased from Sigma-Aldrich, except $\mathrm{Pd}\left(\mathrm{PPh}_{3}\right)_{4}$ which was purchased from Strem chemical and used as received. The silica gel used for column chromatography was purchased from Merck. The deuterated NMR solvents were purchased from Euriso-top. The NMR spectra were recorded using a Bruker AC-300 MHz spectrometer. The two molecules, 10,10'-di-(4"'-cyanophenyl)-9, $9^{\prime}$-bianthryl (CPBA) and 10,10' di-(4"-pyridyl)-9, $9^{\prime}$-bianthryl (PBA) were synthesized by a procedure adapted from the literature [26,27]. Basically, 10,10'-dibromo-9, $9^{\prime}$-bianthryl, $4^{\prime}$-cyanophenyl boronic acid pinacol ester or 4'-pyridyl boronic acid pinacol ester, cesium carbonate and $\mathrm{Pd}\left(\mathrm{PPh}_{3}\right)_{4}$ as a catalyst were dissolved in tetrahydrofuran. The resulting white solid was purified by column chromatography (silica gel, cyclohexane/dichloromethane 1:1) to give a white solid [28].

\subsection{STM Experiments}

The first step consists of the preparation of the $\mathrm{Au}(111)$ surface by argon ions sputtering cycles at $1.2 \mathrm{kV}$ followed by thermal annealing at $673 \mathrm{~K}$. This takes place inside a preparation chamber maintained under UHV conditions with a base pressure lower than $2 \times 10^{-10}$ mbar and coupled to an Omicron variable temperature Scanning Tunneling Microscope (Omicron VT-STM XA). Once the cleanness of Au(111) surface is confirmed by analysis of STM images, we proceed to the deposition of molecules by thermal sublimation from a quartz crucible with corresponding temperature of $458 \mathrm{~K}$ for PBA and $468 \mathrm{~K}$ for CPBA. During deposition the substrate was held at room temperature then transferred and cooled to $110 \mathrm{~K}$ on the STM stage for acquiring images. Each image process was carried out using SPIP 6.7.7 (Digital Surf, France) software.

\section{Results}

We synthesized two molecules, 10,10'-di(4" -pyridyl)-9,9'-bianthryl (PBA) and 10,10'di( $4^{\prime \prime}$-cyanophenyl)-9,9'-bianthryl (CPBA) respectively, that contain two aryl groups covalently bound to the 10 and $10^{\prime}$ positions (Figure 1) of a bianthryl core, respectively. We chose cyanophenyl and pyridyl groups as lateral groups because they are involved in the formation of supramolecular networks on various kinds of surface even at room temperature [5,29]. The distance between the extremities of anthracenly rings of these two molecules is $0.79 \mathrm{~nm}$ and their length is 1.67 and $2.08 \mathrm{~nm}$ for PBA and CPBA, respectively (Figure 1).

\subsection{Supramolecular Self-Assembly on an Au(111) Surface}

PBA and CPBA molecules were deposited by thermal sublimation under UHV on an $\mathrm{Au}(111)$ substrate maintained at room temperature. Molecules were deposited in different coverage ratios but never exceeding the one monolayer threshold. As revealed in STM images recorded at $110 \mathrm{~K}$, no isolated molecule was observed but only large extended 2D islands. Indeed, despite the amounts of molecules deposited on the surface, only 2Dextended islands were observed, each building-up of highly organized periodic protrusions, as shown in Figure 2. 


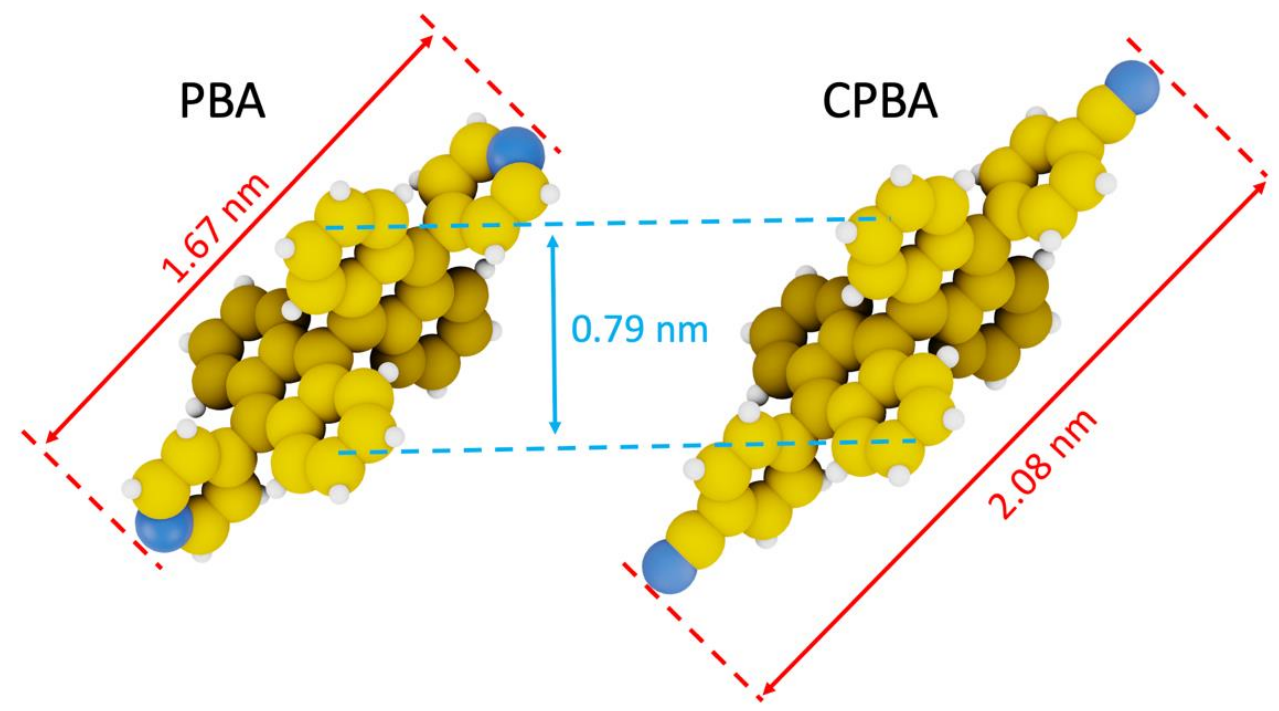

Figure 1. CPK models of 10,10'-di-(4" -pyridyl)-9, $9^{\prime}$-bianthryl (PBA) and 10,10'-di-( $4^{\prime \prime}$-cyanophenyl)9,9'-bianthryl (CPBA) molecules respectively.
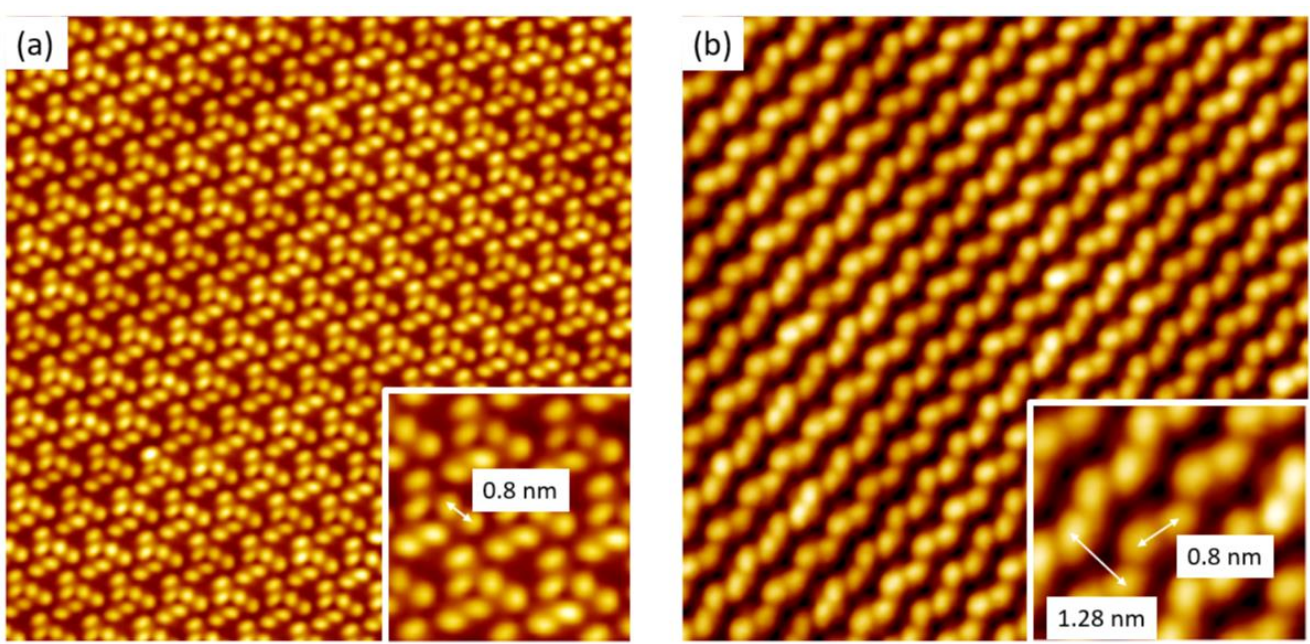

Figure 2. STM images of self-assembled molecules on Au(111) surface. (a) PBA supramolecular network (Vs $=-1.5 \mathrm{~V}$, It $=10 \mathrm{pA}, 30 \mathrm{~nm} \times 30 \mathrm{~nm}$, inset $4 \mathrm{~nm} \times 4 \mathrm{~nm})($ b) CPBA supramolecular network $(V s=1.5 \mathrm{~V}$, It $=10 \mathrm{pA}, 20 \mathrm{~nm} \times 20 \mathrm{~nm}$, inset $3 \mathrm{~nm} \times 3 \mathrm{~nm})$.

In the case of PBA/ $\mathrm{Au}(111)$ interface, repetitive unit consists of three pairs of disjoined protrusions (Figure $2 \mathrm{a}$ ) rotated by $120^{\circ}$. In each domain, all repetitive units are rotated only clockwise or only anti-clockwise, leading to homochiral domains. The distance measured between the disjoined protrusions, is $0.8 \pm 0.02 \mathrm{~nm}$. For the CPBA molecules deposited on $\mathrm{Au}(111)$, a compact periodic network constituted by bright lines, which were separated by darker strips can be observed. The periodicity between the bright lines is $1.28 \pm 0.02 \mathrm{~nm}$. Each line is made up of paired bright protrusions separated by $0.8 \pm 0.02 \mathrm{~nm}$.

Based on our STM observations and measurements, we propose the models of $\mathrm{PBA} / \mathrm{Au}(111)$ and $\mathrm{CPAB} / \mathrm{Au}(111)$, respectively. Consistent with the features of PBA and CPBA molecules (Figure 1), each bright-paired protrusion is attributed to a single PBA or CPBA molecule respectively.

In the case of PBA/ $\mathrm{Au}(111)$ interface, the unit cell of the supramolecular network is constituted by three paired-bright protrusions included in a rhomb, as shown by the two vectors $\mathrm{U}_{\mathrm{PBA}}$ and $\mathrm{V}_{\mathrm{PBA}}$ (Figure $3 \mathrm{a}$ ). The length of these two vectors are $\mathrm{U}_{\mathrm{PBA}}=2.25 \pm 0.22 \mathrm{~nm}$ and $\mathrm{V}_{\mathrm{PBA}}=2.25 \pm 0.22 \mathrm{~nm}$. The unit cell covering $4.38 \mathrm{~nm}^{2}$ for three PBA molecules, the molecular density of the PBA/ $\mathrm{Au}(111)$ network is 0.68 molecule per $\mathrm{nm}^{2}$. The supramolec- 
ular arrangement of PBA/ $\mathrm{Au}(111)$ is obtained thanks to molecule-molecule interactions. The main molecule-molecule contribution is due to the interaction of nitrogen atoms of pyridyl groups pointing towards the centre of an anthracenyl ring of the adjacent PBA molecule (Figure $3 b$ ), corresponding to T-Shape $\pi-\pi$ interaction [30].
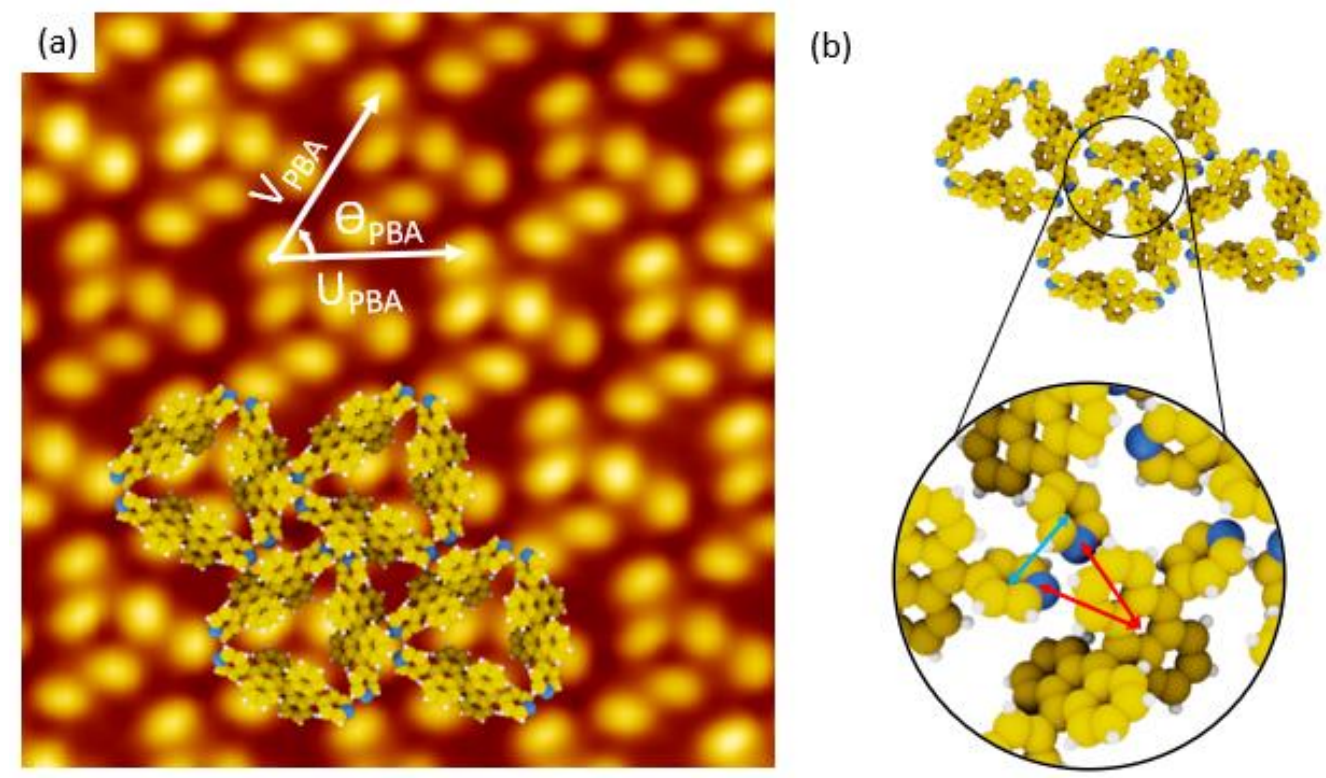

Figure 3. (a) STM image (Vs $=-1.5 \mathrm{~V}$, It $=10 \mathrm{pA}, 8 \mathrm{~nm} \times 8 \mathrm{~nm})$ of PBA supramolecular network with corresponding superimposed model and unit cell vectors: $U_{\mathrm{PBA}}=2.25 \mathrm{~nm}, \mathrm{~V}_{\mathrm{PBA}}=2.25 \mathrm{~nm}$, $\theta_{\mathrm{PBA}}=60^{\circ}$. (b) Supramolecular model of PBA molecules on $\mathrm{Au}(111)$ surface with the inset of magnified image representing three adjacent PBA molecules, where two adjacent pyridyl rings are separated by a distance of $0.42 \mathrm{~nm}$ (blue arrow) and two nitrogen atoms point towards the centre of the anthracenyl ring of a third PBA molecule (highlighted by two red arrow, length: $0.41 \mathrm{~nm}$ ).

CPBA/Au(111) interface is described by an unit cell including two paired-bright protrusions. The unit cell is quite rectangular as shown by the vectors $\mathrm{U}_{\mathrm{CPBA}}$ and $\mathrm{V}_{\mathrm{CPBA}}$ (Figure $4 \mathrm{a}$ ). The length of $\mathrm{U}_{\mathrm{CPBA}}$ vector is $2.58 \pm 0.26 \mathrm{~nm}$ while the length of $\mathrm{V}_{\mathrm{CPBA}}$ vector is $=1.45 \pm 0.15 \mathrm{~nm}$. The $\mathrm{U}_{\mathrm{CPBA}}, \mathrm{V}_{\mathrm{CPBA}}$ angle is $94^{\circ}$. As the unit cell contains two PBA molecules for an area of $3.73 \mathrm{~nm}^{2}$, the molecular density of the CPBA/Au(111) network is 0.54 molecule per $\mathrm{nm}^{2}$, which is lower than those of PBA/Au(111) interface. This supramolecular network is supported by $\pi-\pi$ interaction called T-shaped interaction [31] because the two nitrogen atoms of each CPBA molecule are pointed towards the centre of the anthracenyl ring of the adjacent CPBA molecule included in two surrounding lines of CPBA molecules (Figure 4b). In each unit cell, the two CPBA molecules are diastereo-isomer because of the relative orientation of their bianthryl core (Figure 4a).

\subsection{Annealing of the Supramolecular Self-Assemblies on an Au(111) Surface}

Then, we investigated the chemical transformation of the two supramolecular selfassemblies induced by thermal annealing. Hence, a set of experiments consisting of the subsequent annealing of each observed supramolecular network were conducted. From room temperature to $623 \mathrm{~K}$, we did not observe any modification of the networks. However, at $623 \mathrm{~K}$, a critical transformation was observed. Then, until $773 \mathrm{~K}$, we did not observe other transformations but only noticeable desorption of formed nanostructures at $773 \mathrm{~K}$. In addition, the duration of each step of annealing varied from $1 \mathrm{~h}$ to $4 \mathrm{~h}$, but no effect of duration was observed. 

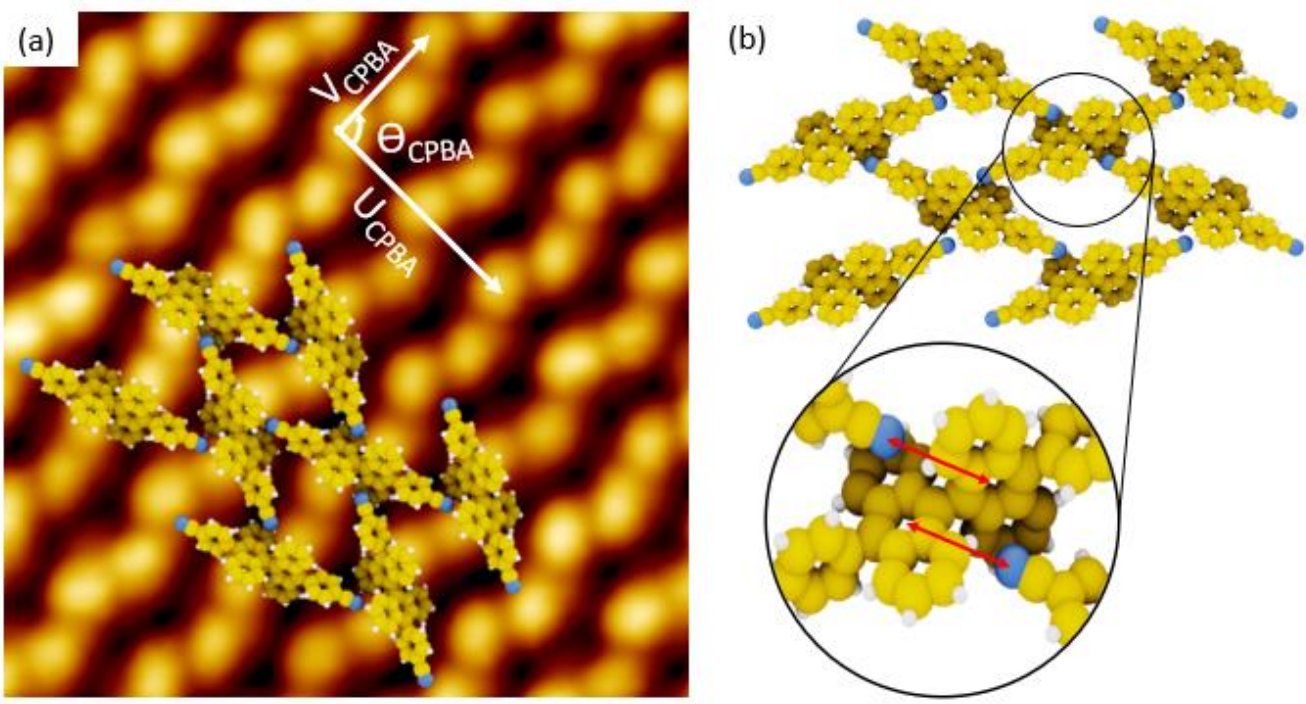

Figure 4. (a) STM image (Vs $=1.5 \mathrm{~V}$, It $=10 \mathrm{pA}, 8 \mathrm{~nm} \times 8 \mathrm{~nm})$ of CPBA supramolecular network with corresponded superimposed supramolecular model and unit cell vectors: $\mathrm{U}_{\mathrm{CPBA}}=2.58 \mathrm{~nm}$, $\mathrm{V}_{\mathrm{CPBA}}=1.45 \mathrm{~nm}, \theta_{\mathrm{CPBA}}=94^{\circ}$. (b) $3 \mathrm{D}$ model of $\mathrm{CPBA} / \mathrm{Au}(111)$. Inset highlights the interaction between one nitrogen atom pointing out the center of anthracenyl ring of the adjacent molecule, which are separated by $0.45 \mathrm{~nm}$ (red arrow).

The thermal annealing of the two periodic supramolecular networks described previously led to disordered annealing nanostructures (Figure 5). In addition, instead of bright-paired protrusions, nanostructures are constituted by cross-shaped bright protrusions. The length of these protrusions is $1.73 \pm 0.05 \mathrm{~nm}$ and $2.23 \pm 0.05 \mathrm{~nm}$ for PBA and CPBA respectively while their width is $1.05 \pm 0.05 \mathrm{~nm}$. The bright protrusions led to the formation of straight or reticulated nanolines including three- of four connecting nodes. The distance separating bright protrusions is longer in the case of CPBA than in the case of PBA (Figure 5).
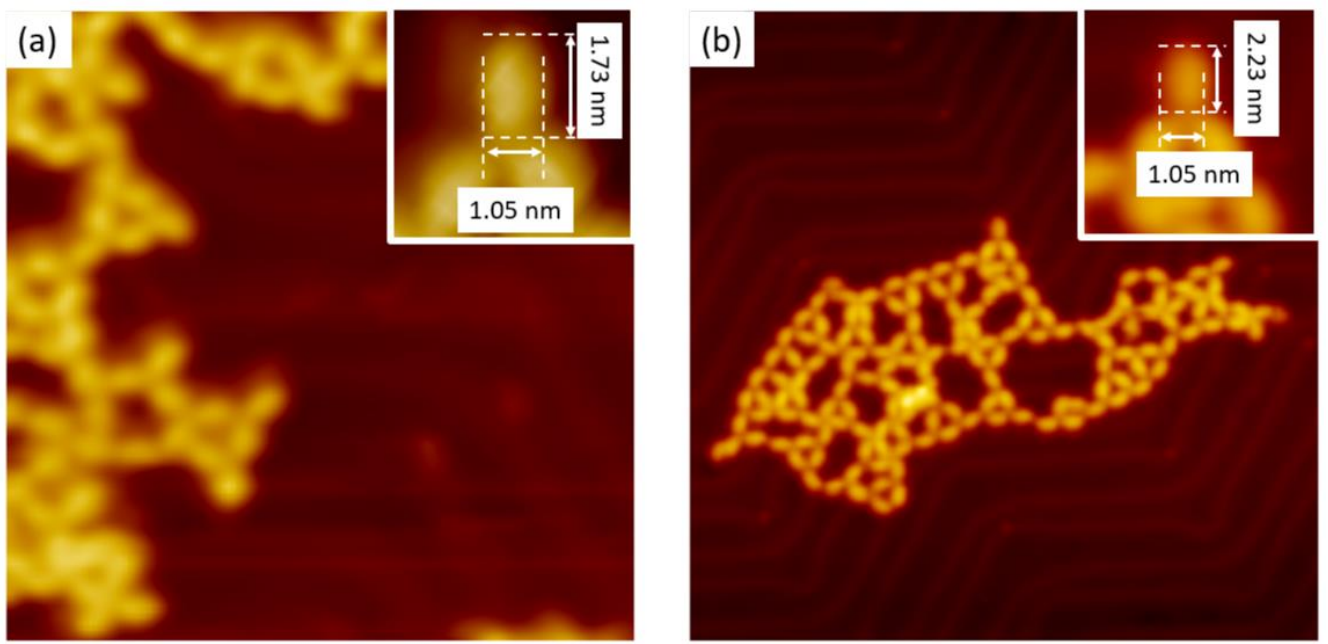

Figure 5. STM images of formed nanostructures observed on $\mathrm{Au}(111)$ surface after thermal annealing of supramolecular networks up to $673 \mathrm{~K}$. (a) PBA (Vs $=-1.7 \mathrm{~V}$, It $=10 \mathrm{pA}, 30 \mathrm{~nm} \times 30 \mathrm{~nm})$ inset $3 \mathrm{~nm} \times 3 \mathrm{~nm},(\mathbf{b}) \mathrm{CPBA}(\mathrm{Vs}=-2.0 \mathrm{~V}$, It $=7 \mathrm{pA}, 60 \mathrm{~nm} \times 60 \mathrm{~nm}$, inset $3.5 \mathrm{~nm} \times 3.5 \mathrm{~nm})$.

\section{Discussion}

The on-surface behavior of bianthryl derivatives has been intensively investigated since it has been shown that most of this type of compound can be polymerized into graphene nanoribbons $[7,11,28,32-38]$. This polymerization occurs in two steps, the first 
being formation of a protopolymer and the second step of this process is based on surfaceassisted intramolecular cyclodehydrogenation providing completely planar building blocks. This cyclodehydrogenation reaction occurs at around $550 \mathrm{~K}$ and $700 \mathrm{~K}$ on a $\mathrm{Cu}(111)$ and $\mathrm{Au}(111)$, respectively [33]. This difference of temperature outlines the role of the surface in this intramolecular cyclodehydrogenation. The driven force of cyclodehydrogenation is the formation of more conjugated compounds. One consequence of this increasing of conjugation is the flattening of involved molecules. However, on $\mathrm{Cu}(111)$, if the positions 10 and $10^{\prime}$ of the starting bianthryl are substituted by an aryl ring, the formation of protopolymers is not possible and only disordered polymeric structures were obtained due to the strong reactivity of the $\mathrm{Cu}(111)$ surface which lead to the formation of reactive radicals [18].

On the basis of the features observed in STM images, we can attribute the bright protrusions (Figure 5) to the 7,14-(4'-pyridyl)-bisanthene (flat-PBA) and 7,14-( $4^{\prime}$-cyanophenyl)bisanthene (flat-CPBA) molecules obtained by surface-assisted cyclodehydrogenation of PBA and CPBA respectively (Figure 6).

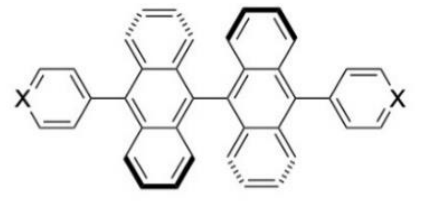

$\mathrm{X}=\mathrm{N}$

10,10'-di(4"-pyridyl)-9,9'-bianthryl (PBA) $\mathrm{X}=\mathrm{C}-\mathrm{CN} \quad 10,10^{\prime}$-di(4"-cyanophenyl)-9,9'-bianthryl (PBA)

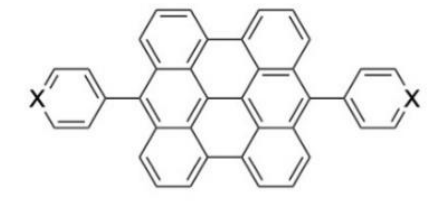

$\mathrm{X}=\mathrm{N} \quad$ 7,14-di(4'-pyridyl)-bisanthene $\mathrm{X}=\mathrm{C}-\mathrm{CN}$ 7,14-di(4'-cyanophenyl)-bisanthene (flat-CPBA)

Figure 6. Thermal-induced cyclodehydrogenation of PBA and CPBA molecules. The starting PBA and CPBA molecules have a 3D cross-shaped core (i.e., bianthryl core), the corresponding bisanthene cores (Flat-PBA and flat-CPAB) are flattened.

As $\mathrm{Au}(111)$ surface is less reactive than $\mathrm{Cu}(111)$ surface and as the 10 and $10^{\prime}$-positions are substituted in PBA and CPBA molecules, no polymerisation occurs by thermal annealing [39]. Only intramolecular cyclodehydrogenations are possible, leading to flattened molecules, flat-PBA and flat-CPBA, respectively.

The average distance between $\mathrm{Au}(111)$ surface and flat-PBA or flat-CPBA molecules is shorter than those between surface and respectively, PBA and CPBA (Figure 7). Therefore, the interaction of nitrogen atoms of pyridyl or cyanophenyl moieties with the gold atoms of the surface is reinforced, that promotes the formation of coordination polymers $[2,22-24,40-42]$.

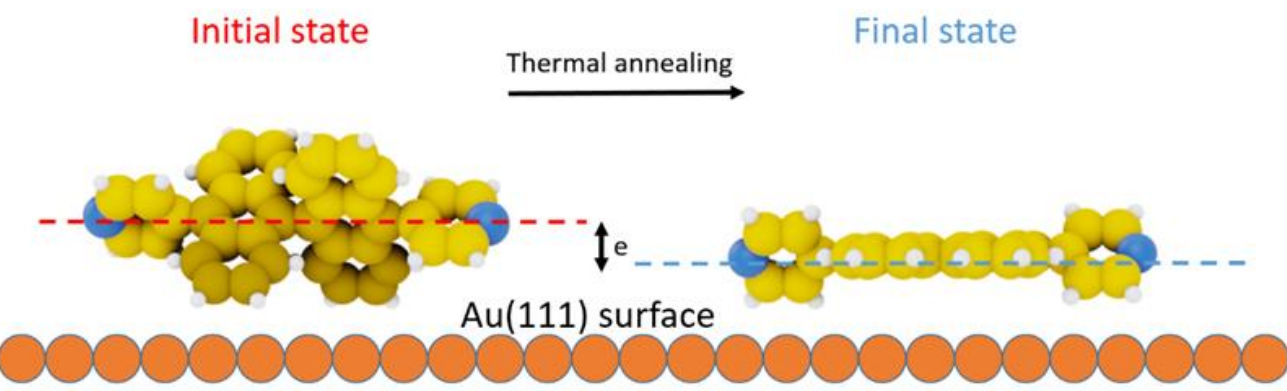

Figure 7. CPK model of PBA and flat-PBA highlighting the decreasing of molecule-surface distance by $0.24 \mathrm{~nm}$ due to the flattening of PBA induced by thermal annealing.

The pyridyl or cyano moiety are ligand for several kind of metal atoms, due to the presence of the lone pair of electrons on the nitrogen atom. Due to the strength and the directionality of these metal-ligand bond, the corresponding coordination polymers exhibit a high degree of reticulation on metal substrates like on an $\mathrm{Au}(111)$ surface, even if it is 
still rare compared to other coinage surfaces [22,25,41,42]. These coordination properties support the observation of straight and reticulated nanolines in STM images.

The straight lines observed in Figure 5 correspond to the coordination of two flat-PBA (Figure $8 \mathrm{a}, \mathrm{d}$ ) or flat-CPBA (Figure 9a,d) molecules surrounding a gold adatom, which is visible as bright protrusion for coordination polymers including flat-PBA. The three- and four reticulating nodes observed in STM images are attributed to three- or four flat-PBA (Figure $8 \mathrm{~b}-\mathrm{d}$ ) or flat-CPBA molecules (Figure $9 \mathrm{~b}-\mathrm{d}$ ) coordinating one gold adatom. Neither of these modes can form a long-range ordered lattice on $\mathrm{Au}(111)$ surface. The lack of long-range polymer can be explained by the softness of gold adatom compared to Co or Fe cations which lead to well-organized 1D/2D networks with hard nitrogen-based ligands [42].

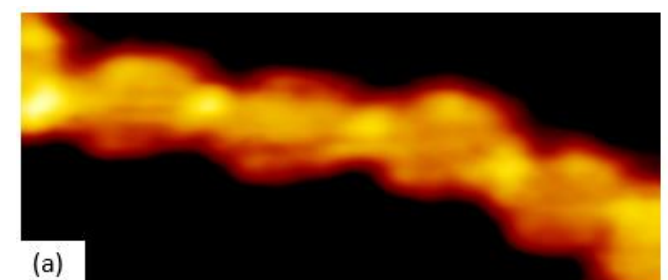

(d)
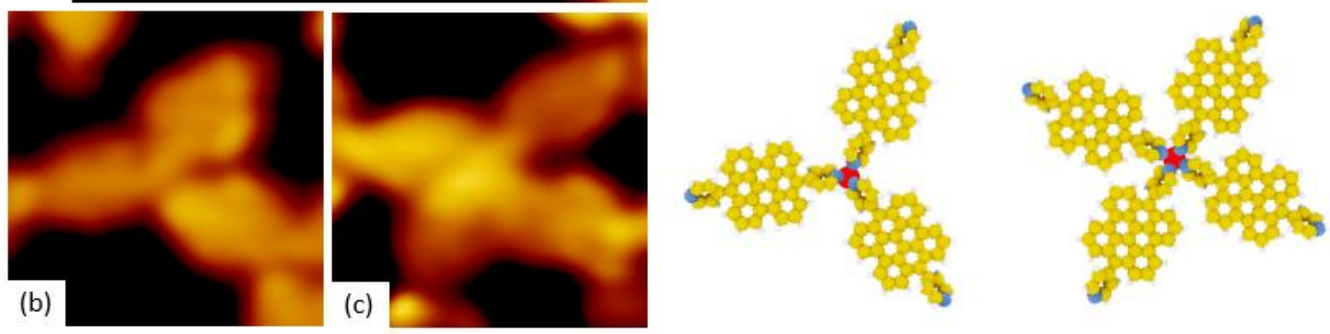

Figure 8. $(\mathbf{a}-\mathbf{c})$ STM images $(\mathrm{Vs}=-1.8 \mathrm{~V}$, It = $10 \mathrm{pA})$ of PBA supramolecular nanostructures with three different configurations obtained after thermal annealing: (a) Chain-like nanostructures of protrusions $(7 \mathrm{~nm} \times 3 \mathrm{~nm})$, (b) Y-shaped trimer nanostructures $(4 \mathrm{~nm} \times 4 \mathrm{~nm})$ and (c) Cross-shaped of nanostructures $(4 \mathrm{~nm} \times 4 \mathrm{~nm}$ ). (d) Molecular models of the three different type of coordination (red dot: Au ad-atom surrounded by organic moieties).

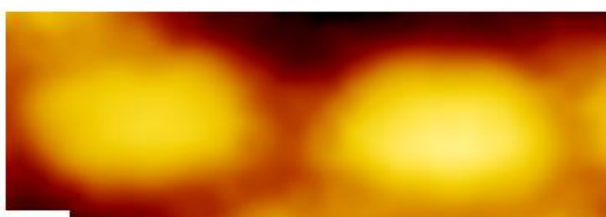

(a)

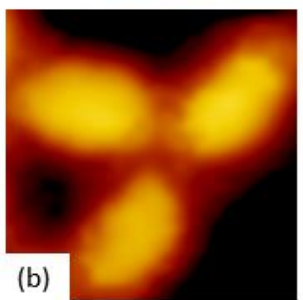

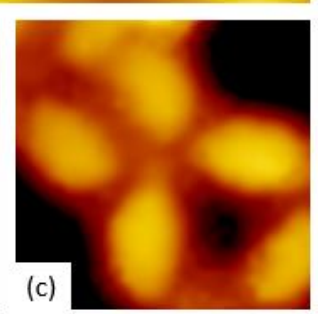

(d)

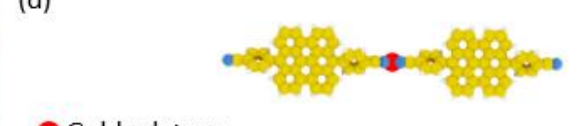

Gold adatom
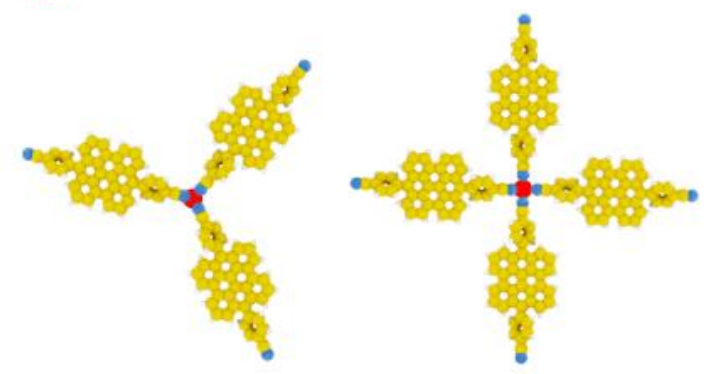

Figure 9. $(\mathbf{a}-\mathbf{c})$ STM images $(\mathrm{Vs}=-2.0 \mathrm{~V}, \mathrm{It}=7 \mathrm{pA})$ of three nanostructures obtained after thermal annealing of CPBA: (a) Rod-like protrusions $(7 \mathrm{~nm} \times 3 \mathrm{~nm})(\mathbf{b})$ Y-shaped trimer of nanostructures $(4 \mathrm{~nm} \times 4 \mathrm{~nm})$ and $(c)$ Cross-shaped nanostructures $(5 \mathrm{~nm} \times 5 \mathrm{~nm})$. (d) Molecular models of three different type of coordination (Red dot: Au ad-atom surrounded by organic moieties).

\section{Conclusions}

We have demonstrated that the balance between molecule-molecule interaction and molecule-surface interaction can be strongly alter by using on-surface chemistry. We have 
shown that 2D-extended periodic supramolecular networks are converted into coordination polymers by a thermal annealing. By flattening molecule, thanks to intramolecular cyclodehydrogenations, pyridyl or cyanophenyl rings can be transformed from pi-pi stacking precursors to coordinating agents of gold adatoms. This strategy paves the way to new possibilities for multi-functional nanostructures by using on-surface assisted synthesis.

Author Contributions: L.M. and S.L. synthetised all molecules. E.G., J.J. and F.P. performed STM experiments. E.G., F.P. and F.C. wrote the manuscript with inputs from all authors. All authors have read and agreed to the published version of the manuscript.

Funding: This research was funded by Agence Nationale de la Recherche, grant number OVATION ANR-19-CE09-0020 and the Pays de Montbéliard Agglomération.

Conflicts of Interest: The authors declare no conflict of interest.

\section{References}

1. Xing, L.; Peng, Z.; Li, W.; Wu, K. On Controllability and Applicability of Surface Molecular Self-Assemblies. Acc. Chem. Res. 2019, 52, 1048-1058. [CrossRef]

2. Barth, J.V.; Costantini, G.; Kern, K. Engineering Atomic and Molecular Nanostructures at Surfaces. Nature 2005, 437, 671-679. [CrossRef] [PubMed]

3. Kudernac, T.; Lei, S.; Elemans, J.A.; De Feyter, S. Two-Dimensional Supramolecular Self-assembly: Nano-Porous Networks on surfaces. Chem. Soc. Rev. 2009, 38, 402-421. [CrossRef] [PubMed]

4. Sosa-Vargas, L.; Kim, E.; Attias, A.-J. Beyond “Decorative” 2D Supramolecular Self-Assembly: Strategies Towards Functional Surfaces for Nanotechnology. Mater. Horiz. 2017, 4, 570-583. [CrossRef]

5. Makoudi, Y.; Jeannoutot, J.; Palmino, F.; Chérioux, F.; Copie, G.; Krzeminski, C.; Cléri, F.; Grandidier, B. Supramolecular self-assembly on the B-Si(111)- $(\sqrt{ } 3 x \sqrt{ } 3)$ R30 ${ }^{\circ}$ surface: From Single Molecules to Multicomponent Networks. Surf. Sci. Rep. 2017, 72, 316-349. [CrossRef]

6. Grill, L.; Dyer, M.; Lafferentz, L.; Persson, M.V.; Hecht, S. Nano-Architectures by Covalent Assembly of Molecular Building Blocks. Nat. Nanotech. 2007, 2, 687-691. [CrossRef]

7. Cai, L.; Ruffieux, P.; Jaafar, R.; Bieri, M.; Braun, T.; Blankenburg, M.; Seitsonen, A.P.; Saleh, M.; Feng, X.; Mullen, K.; et al. Atomically Precise Bottom-Up Fabrication of Graphene Nanoribbons. Nature 2010, 466, 470-473. [CrossRef]

8. Matena, M.; Riehm, T.; Stöhr, M.; Jung, T.A.; Gade, L.H. Transforming Surface Coordination Polymers into Covalent Surface Polymers: Linked Polycondensed Aromatics through Oligomerization of N-Heterocyclic Carbene Intermediates. Angezw. Chem. Int. Ed. 2008, 47, 2414-2417. [CrossRef] [PubMed]

9. Palmino, F.; Loppacher, C.; Chérioux, F. Photochemistry Highlights on On-Surface Synthesis. ChemPhysChem 2019, 20, 2271-2280. [CrossRef]

10. Held, P.A.; Fuchs, H.; Studer, A. Covalent-Bond Formation via On-Surface Chemistry. Chem. Eur. J. 2017, 23, 5874-5892. [CrossRef]

11. Sakaguchi, H.; Song, S.; Kojima, T.; Nakae, T. Homochiral Polymerization-Driven Selective Growth of Graphene Nanoribbons. Nat. Chem. 2017, 9, 57-63. [CrossRef]

12. Pvalicek, N.; Majzik, Z.; Collazos, S.; Meyer, G.; Perez, D.; Guitian, E.; Pena, D.; Gross, L. Generation and Characterization of ameta-Aryne on $\mathrm{Cu}$ and $\mathrm{NaCl}$ Surfaces. ACS Nano 2017, 11, 10768-10773. [CrossRef]

13. Para, F.; Bocquet, F.; Nony, L.; Loppacher, C.; Féron, M.; Chérioux, F.; Gao, D.Z.; Canova, F.F.; Watkins, M.B. Micrometre-Long Covalent Organic Fibres by Photoinitiated Chain-Growth Radical Polymerization on an Alkali-Halide Surface. Nat. Chem. 2018, 10, 1112-1117. [CrossRef] [PubMed]

14. Kawai, S.; Sang, H.; Kantorovitch, L.; Takahashi, K.; Nozaki, K.; Ito, S. An Endergonic Synthesis of Single Sondheimer-Wong Diyne by Local Probe Chemistry. Angew. Chem. Int. Ed. 2020, 59, 10842-10847. [CrossRef] [PubMed]

15. Yang, B.; Dong, B.; Chi, L. On-Surface Intramolecular Reactions. ACS Nano 2020, 14, 6376-6382. [CrossRef]

16. Clair, S.; de Oteyza, D.G. Controlling a Chemical Coupling Reaction on a Surface: Tools and Strategies for On-Surface Synthesis. Chem. Rev. 2019, 119, 4717-4776. [CrossRef]

17. Lackinger, M. On-Surface Polymerization-A Versatile Synthetic Route to Two-Dimensional Polymers: On-surface Polymerization. Polym. Inter. 2015, 64, 1073-1078. [CrossRef]

18. Geagea, E.; Jeannoutot, J.; Féron, M.; Palmino, F.; Thomas, C.M.; Rochefort, A.; Chérioux, F. Collective Radical Oligomerisation Induced by STM Tip on a Silicon Surface. Nanoscale 2021, 13, 349-351. [CrossRef]

19. Grossmann, L.; King, B.T.; Reichlmaier, S.; Hartmann, N.; Rosen, J.; Heckl, W.M.; Bjork, J.; Lackinger, M. On-Surface Photopolymerization of Two-dimensional Polymers Ordered on the Mesoscale. Nat. Chem. 2021, 13, 730-736. [CrossRef]

20. Grill, L.; Hecht, S. Covalent on-Surface Polymerization. Nat. Chem. 2020, 12, 115-130. [CrossRef] [PubMed]

21. Schlickhum, U.; Decker, R.; Klappenberger, F.; Zoppellaro, G.; Klyatskaya, S.; Ruben, M.; Silanes, I.; Arnau, A.; Kern, K.; Brune, H.; et al. Metal-Organic Honeycomb Nanomeshes with Tunable Cavity Size. Nano Lett. 2007, 7, 3813-3817. [CrossRef]

22. Dong, L.; Gao, Z.; Lin, N. Self-Assembly of Metal-Organic Coordination Structures on Surfaces. Prog. Surf. Sci. 2016, 91, 101-135. [CrossRef] 
23. Moreno-Lopez, J.C.; Perez Paz, A.; Gottardi, S.; Solianyk, L.; Li, J.; Monjas, L.; Hirsch, A.K.H.; Mowbray, D.C.; Stohr, M. Unveiling Adatoms in On-Surface Reactions: Combining Scanning Probe Microscopy with van't Hoff Plots. J. Phys. Chem. C 2021, 125, 9847-9854. [CrossRef]

24. Bartels, L. Tailoring Molecular Layers at Metal Surfaces. Nat. Chem. 2010, 2, 87-95. [CrossRef]

25. Koepf, M.; Chérioux, F.; Wytko, J.A.; Weiss, J. 1D and 3D Surface-Assisted Self-Organization. Coord. Chem. Rev. 2012, 256, 2872-2892. [CrossRef]

26. Natarajan, P.; Schmittel, M.J. Photoluminescence, Redox Properties, and Electrogenerated Chemiluminescence of Twisted 9,9'-Bianthryls. J. Org. Chem. 2013, 78, 10383-10394. [CrossRef]

27. Miyaura, N.; Suzuki, A. Palladium-Catalyzed Cross-Coupling reactions of Organoboron Compounds. Chem. Rev. 1995, 95, 2457-2483. [CrossRef]

28. Geagea, E.; Jeannoutot, J.; Morgenthaler, L.; Lamare, S.; Rochefort, A.; Palmino, F.; Chérioux, F. Unravelling the Growth Mechanism of $(3,1)$ Graphene Nanoribbons on a Cu(111) Surface. Chem. Commun. 2021, 57, 6043-6045. [CrossRef]

29. Elemans, J.A.A.W.; Lei, S.; De Feyter, S. Molecular and Supramolecular Networks on Surfaces: From Two-Dimensional Crystal Engineering to Reactivity. Angew. Chem. Int. Ed. 2009, 48, 7298-7332. [CrossRef]

30. Mishra, B.K.; Sathyamurthy, N. $\pi-\pi$ interaction in Pyridine. J. Phys. Chem. A 2005, 109, 6-8. [CrossRef]

31. Martinez, C.R.; Iverson, B.L. Rethinking the term "pi-stacking". Chem. Sci. 2012, 3, 2191-2201. [CrossRef]

32. Trier, M.; Pignedoli, C.A.; Laino, T.; Rieger, R.; Mullen, K.; Passerone, D.; Fasel, F. Surface-Assisted Cyclodehydrogenation Provides a Synthetic Route Towards Easily Processable and Chemically Tailored Nanographenes. Nat. Chem. 2010, 3, 61-67. [CrossRef]

33. Tarliz, L.; Ruffieux, P.; Fasel, F. On-Surface Synthesis of Atomically Precise Graphene Nanoribbons. Adv. Mater. 2016, 28, 6222-6231. [CrossRef]

34. Moreno, C.; Vilas-Varela, M.; Kretz, B.; Garcia-Lekue, A.; Costache, M.; Paradinas, M.; Panighel, M.; Ceballos, G.; Valenzuela, S.O.; Pena, D.; et al. Bottom-up Synthesis of Multifunctional Nanoporous Graphene. Science 2018, 360, 199-203. [CrossRef] [PubMed]

35. Kawai, S.; Nakatsuka, S.; Hatakeyama, T.; Pawlak, R.; Meier, T.; Tracey, J.; Meyer, E.; Foster, A.S. Multiple Heteroatom Substitution to Graphene Nanoribbon. Sci. Adv. 2018, 4, eaar7181. [CrossRef]

36. Sanchez-Sanchez, C.; Dienel, T.; Deniz, O.; Ruffieux, P.; Berger, R.; Feng, X.; Mullen, K.; Fasel, R. Purely Armchair or Partially Chiral: Noncontact Atomic Force Microscopy Characterization of Dibromo-Bianthryl-Based Graphene Nanoribbons Grown on $\mathrm{Cu}(111)$. ACS Nano 2016, 10, 8006-8011. [CrossRef] [PubMed]

37. Schulz, F.; Jacobse, P.H.; Canova, F.F.; van der Lit, J.; Gao, D.Z.; von den Hoogenband, A.; Han, P.; Kelin Gebbink, R.J.M.; Moret, M.-E.; Joensuu, P.M.; et al. Precursor Geometry Determines the Growth Mechanism in Graphene Nanoribbons. J. Phys. Chem. C 2017, 121, 2896-2904. [CrossRef]

38. de Oteyza, D.G.; Garcia-Lekue, A.; Vilas-Varela, M.; Merino-Diez, N.; Carbonell-Sanroma, E.; Corso, M.; Vasseur, G.; Rogero, C.; Guitan, E.; Pascual, J.I.; et al. Substrate-Independent Growth of Atomically Precise Chiral Graphene Nanoribbons. ACS Nano 2016, 10, 9000-9008. [CrossRef]

39. Wang, X.-Y.; Dienel, T.; Di Giovannantonio, M.; Barin, B.G.; Kharche, N.; Deniz, O.; Urgl, J.I.; Widmer, R.; Stolz, S.; De Lima, L.H.; et al. Heteroatom-Doped Perihexacene from a Double Helicene Precursor: On-Surface Synthesis and Properties. J. Am. Chem. Soc. 2017, 139, 4671-4674. [CrossRef]

40. Heim, D.; Ecija, D.; Seufert, K.; Auwarter, W.; Aurisicchio, C.; Fabbro, C.; Bonifazi, D.; Barth, J.V. Self-Assembly of Flexible One-Dimensional Coordination Polymers on Metal Surfaces. J. Am Chem. Soc. 2010, 132, 6783-6790. [CrossRef]

41. Fan, Q.; Wang, C.; Han, Y.; Zhu, J.; Kuttner, J.; Hilt, G.; Gottfried, J.M. Surface-Assisted Formation, Assembly, and Dynamics of Planar Organometallic Macrocycles and Zigzag Shaped Polymer Chains with C-Cu-C Bonds. ACS Nano 2014, 8, 709-718. [CrossRef] [PubMed]

42. Pham, T.A.; Song, F.; Alberti, M.N.; Nguyen, M.-T.; Trapp, N.; Thilgen, C.; Diedrich, F.; Stöhr, M. Heat-induced formation of one-dimensional coordination polymers on $\mathrm{Au}(111)$ : An STM study. Chem. Commun. 2014, 51, 14473. [CrossRef] [PubMed] 